\title{
editorial
}

\section{Towards an archaeology of invented and imaginary landscapes}

\begin{abstract}
Landscape is a theme with a long standing in archaeology. But whereas archaeologists in the
\end{abstract} 1960 s analyzed the carrying capacity of the environment in order to measure human adaptation, since the 1990s landscapes are increasingly being 'read' for understanding how people related to the land. The shift in perspective is clearly a substantial one which does not merely demonstrate a development of archaeological thought: as related developments in human geography and anthropology show, it is rooted in a wider current in the Western world of rethinking fundamental notions such as 'nature', 'culture' and 'society'. The concept of 'landscape' or perhaps more generally that of 'space' also fits in this series, as was argued by among others Michel Foucault, who claimed that 'the present epoch will perhaps be above all the epoch of space' (Foucault 1986, 22).

Landscapes are now recognized as largely having been shaped by their inhabitants through daily routine practices as well as by the conscious creation of ritual spaces. In this view, the term 'landscape' necessarily comprises all human remains and thus contrasts considerably with conventional archaeological usage, in which it was implicitly equated with the physical environment. It is argued that landscapes can be regarded as essentially social constructs, which have been structured in accordance with conceptual categorizations of its inhabitants. Studying landscape from these perspectives has thus opened up promising ways of examining both social and symbolic categorizations of its inhabitants. As several pioneering studies of the 'monumental' landscapes of southern England and Sweden have shown (e.g. Tilley 1994), a landscape can rightfully be regarded as no less than 'the most solid appearance in which a history can declare itself (Inglis 1977, 489).

Archaeological Dialogues has from the very start offered a forum of debate for precisely this type of discussions in archaeology. Under the heading of 'cultural landscapes' attention has particularly been focused on the question how archaeologists can study the immaterial dimensions of past landscapes and how material remains from the past are perceived in present-day landscapes. Both strands in the debate have repeatedly been taken up in past issues of Archaeological Dialogues: both Roymans (1995) and Fontijn (1996) have explored how archaeological remains have been reconceptualized and accordingly reused in the past. Kolen (1995) has in contrast addressed the problem of the rapid destruction of contemporary landscapes by examining the ways in which landscapes are nowadays perceived in western Europe and by considering what this entails for their preservation. The implications of archaeological remains in contemporary landscapes also constituted a major topic at the international 'Symposium on Archaeology and Theory', which was organized by the Archaeological Dialogues foundation in Leiden from 17-19 January 1995. Under the general heading of The history, theory and 
methodology of regional archaeological projects various aspects of recent work in both northwestern Europe and the Mediterranean were discussed, including matters of archaeological heritage and cultural identity. A closely related set of papers examining shifts in theoretical perspectives and methodological approaches of specific regional projects has previously been published in Archaeological Dialogues 3.2 (1996, 137-255).

In the current issue of Archaeological Dialogues discussion is again focused on the immaterial aspects of landscape in three discussion articles, one interview and one note which together cover landscape in the broadest sense of the word. Although not explicitly conceived as such, the felicitous combination of three papers originally presented at the 'Archaeology and Theory' symposium with a long discussion paper and an interview has not only resulted in a coherent collection of papers but it also testifies to the aforementioned general interest in landscape.

Two themes in particular stand out in this issue: one regards the cosmological foundations of landscape perceptions and related patterns of material culture in the landscape. They are aptly labeled 'landscapes of the imagination' by Richard Bradley in his paper on the wellknown prehistoric landscapes of Cranborn Chase and are suggested as a possible explanation of the remarkable apparent lack of continuity between on the one hand the late Neolithic and Early Bronze Age monumental landscapes and on the other hand the more 'mundane' ones of the Middle Bronze Age and later: while distinct in appearance, they are argued to have rooted in similar imaginary landscapes. The second theme has been captured by Ton Lemaire under the heading of 'invented landscapes', who focuses instead on the ideological connotations of the very notion of landscape itself. In his seminal discussion paper he exposes it as a specifically Western product of the enlightenment and modernity and suggests that using the notion of landscape may reveal more about (post-)modern archaeologists than about social or cosmological perceptions of premodern societies. In addition, Lemaire argues that archaeology as a discipline is a product of modernity and as such actively involved in the modernization of landscape, which in practice means the destruction of premodern landscapes. Lemaire's antimodernist representation of landscape and the inhabitants dwelling in it are extensively commented upon by two geographers (Denis Cosgrove and Augustin Berque) and an anthropologist (Tim Ingold). The implications of Lemaire's paper for archaeology will be the object of further discussion in the next issue of Archaeological Dialogues (4.2, autumn 1997).

A crucial aspect of the latter theme is taken up by Michael Fotiadis, who explores why (regional) archaeology has had so little to say about cultural identity which nowadays is widely regarded as a basic feature of landscape. Looking into the aims and concerns of the New Archaeology, he presents a thorough and insightful discussion of underlying modernist assumptions and contrasts these with the recent interest in cultural identity. Originally presented at the Leiden symposium along with the previous paper, Milco Wansleeben points out that innovative methods like GIS do not necessarily entail conceptual improvements but need to be complemented with theoretical considerations about landscape and regional studies.

Landscape finally appears as a dominant theme in the interview with Tjalling Waterbolk, who over the past fifty years has more than anyone else in Dutch archaeology explored the intimate connections between rural history, prehistoric settlement, landscape and nature preservation. Although discussion is largely focused on the recent history of Dutch archaeology 
and its external relationships, landscape turns out not only to represent a recurrent theme in the numerous writings of Waterbolk but also to embody the relationship with deeper concerns about local and regional environment and history.

Finally, the debate on the prospects and pitfalls of a 'Heideggerian archacology' as initiated by Julian Thomas in a previous volume of Archaeological Dialogues (1996) is again taken up in a discussion between Håkan Karlsson and Julian Thomas.

Both the conference in Leiden and the additional pages for the publication of the papers in this and the previous issue of Archaeological Dialogues have been made possible thanks to the generous support of the Dutch National Research School for Advanced Studies in Archaeology ARCHON. (PvD-HF)

\section{References}

Fontijn, D. 1996: Socializing landscape. Second thoughts about the cultural biography of urnfields, Archaeological dialogues 3, 77-87.

Foucault, M. 1986: Of other spaces, Diacritics 16, 22-27.

Inglis, F. 1977: Nation and community. A landscape and its morality, The sociological review 25, 489-513.

Kolen, J. 1995: Recreating (in) nature, visiting history. Second thoughts on landscape reserves and their role in te preservation and experience of the historic environment, Archaeological dialogues 2, 127-159.

Roymans, N. 1995: The cultural biography of urnfields and the long-term history of a mythical landscape, Archaeological dialogues 2, 2-38.

Thomas, J. 1996, A précis of Time, culture and identity, Archaeological dialogues 3, 6-46.

Tilley, C. 1994: A phenomenology of landscape. Places, paths and monuments, Oxford and Providence (Explorations in anthropology). 